\title{
UN ACERCAMIENTO AL PROBLEMA DE LA LEGITIMIDAD DEL CONTROL JUDICIAL DE CONSTITUCIONALIDAD DESDE LA TEORÍA DE LA DEMOCRACIA DELIBERATIVA
}

\author{
Alfonso Renato Vargas Murillo*
}

\begin{abstract}
RESUMEN: El presente trabajo pretende describir algunas propuestas relacionadas con el control de constitucionalidad desde la teoría de la democracia deliberativa, en cuanto se presenta como un modelo que pretende suplir las "deficiencias" del proceso judicial de declaración de inconstitucionalidad en términos de participación, inclusión y diálogo, elementos centrales en los cuestionamientos sobre la legitimidad democrática de las cortes para ejercer dicha función.
\end{abstract}

PALABRAS CLAVE: Control de constitucionalidad. Democracia deliberativa

\begin{abstract}
This paper aims to describe some proposals related to the control of constitutionality from the theory of deliberative democracy, as it is presented as a model that seeks to replace the "deficiencies" of the judicial process of declaration of unconstitutionality in terms of participation, inclusion and dialogue, central elements in the questions about the democratic legitimacy of the courts to exercise this function.
\end{abstract}

KEYWORDS: Judicial review. Deliberative democracy.

\section{INTRODUCCIÓN}

La justificación tradicional, de la función judicial de controlar la constitución que se remontan a los orígenes del control de constitucionalidad (el caso norteamericano) y que ha recobrado su fuerza en el contexto del Estado Constitucional de Derecho, parte de la idea de una "mejor posición" de los jueces para resolver las controversias respecto a derechos fundamentales o problemas de interpretación constitucional; este "elitismo epistemológi-

* Bachiller en Derecho. Escuela Profesional de Derecho, Facultad de Derecho y Ciencias Políticas, Universidad Privada de Tacna. Correo Electrónico: avargasm95@gmail.com 
co", como lo denomina Carlos NINO, tiene como presupuesto, que la destreza intelectual debe primar por sobre el grado de representación y el equilibrio de los intereses en juego ${ }^{1}$. Esto llevó a autores del neo-constitucionalismo como ZAGREBELSKY a afirmar que "La verdadera democracia es la democracia de los jueces"2 . Frente a esta posición de supremacía judicial, surge otra posición igualmente radical, como es la planteada por los autores encuadrados dentro de la corriente denominada "Constitucionalismo Popular", los cuales cuestionan esa mejor posición de los jueces para resolver conflictos derivados de la interpretación constitucional, partiendo de una comprensión de la constitución como "un documento abierto (...) bien al consenso o al más difundido disenso popular y nunca a la interpretación petrificante de un juez no electo"3 , de esta manera, plantea que ningún órgano derivado o constituido, puede usurpar el lugar del pueblo como creador de la Constitución, lo que lo pondría en mejor posición para determinar el sentido último de su creación: las cláusulas constitucionales ${ }^{4}$.

Sin embargo ambas posiciones llevadas a un extremo, ante la posibilidad de generar graves exclusiones (en términos mayoritarios o minoritarios), resultan cuestionables desde visiones democráticas, formulándose -al menos hasta este punto- una aporía. En el primer caso, dejamos a la sociedad civil fuera del debate sobre el sentido de la Constitución, y en el segundo, el peso de las mayorías podría igualmente dejar a grupos minoritarios fuera de dicha discusión. Esto resulta especialmente problemático en sociedades como la de los países latinoamericanos caracterizadas por la pluralidad, entendiendo "lo plural", como la situación en la que los ciudadanos se adhieren a posiciones diversas y hasta contradictores respecto a sus concepciones del "mundo político y personal", generando la imperiosa necesidad, de diseñar instituciones que "estén dispuestas a convivir con desacuerdos profundos, persistentes, e inerradicables, no solo acerca de lo bueno, sino de lo correcto" .

Frente a tal situación, la democracia deliberativa, nos plantea la posibilidad de construir la legitimidad, ya no desde una supuesta "mejor posición" de los jueces respaldada por el contenido de la Constitución, ni tampoco desde la regla de mayorías, sino desde una comprensión dialógica del constitucionalismo -es decir por su carácter comunicativo- , existiendo solo a partir de diálogo, la intersubjetividad y búsqueda del consenso entre los involucrados, "en el que los resultados serían alcanzados luego de amplios procedimientos de deliberación pública"6.

El presente trabajo pretende describir algunas propuestas relacionadas con el control de constitucionalidad desde la teoría de la democracia deliberativa, en cuanto se presenta

1 LÓPEZ HIDALGO, Pablo. "Legitimidad democrática e interpretación de la Constitución: proyección a la tarea interpretativa de la Corte Constitucional del Ecuador", Tesis para obtener el grado de Doctor en Derecho, Universidad Andina Simón Bolívar, Quito, 2017, p. 47.

2 SANTIAGO, Alfonso. "Sistema Jurídico, Teoría del Derecho y Rol de los Jueces: Las novedades del neoconstitucionalismo" en Revista Díkaion No 22, vol. 17. (2008), pp. 131-155 p. 141.

3 SANIN, Ricardo, Teoría crítica constitucional: rescatando la democracia del liberalismo. Quito, Corte Constitucional para el Período de Transición, 2011, p. 82.

4 ÁLVAREZ, Ramiro, "El Constitucionalismo Popular y los problemas de la 'última palabra': apuntes para un Contexto Latinoamericano" en Revista Jurídica de la Universidad de Palermo Año 13, N¹, (2012), pp. 75-125. p. 83.

5 OLIVARES, Nicolás Emanuel, "Democracia deliberativa y control de constitucionalidad: En defensa de un diseño multisituado" en Revista de Derecho (Barranquilla) $N^{\circ}$ 47, (2017), pp. 167-206, p. 173.

6 GIUFFRÉ. Carlos, "Democracia deliberativa: institucionalización de instrumentos jurídico-dialógicos", Sistema Argentino de Información Jurídica, (2016), p. 2. Disponible en: http://www.saij.gob.ar/ 
como un modelo que pretende suplir las “deficiencias” del proceso judicial de declaración de inconstitucionalidad en términos de participación, inclusión y diálogo, elementos centrales en los cuestionamientos sobre la legitimidad democrática de las cortes para ejercer dicha función.

\section{EL CONTROL DE CONSTITUCIONALIDAD}

La Constitución, como plantea Humberto NOGUEIRA ${ }^{7}$, en tanto instrumento creado con la finalidad de asegurar la convivencia social, al determinar las normas fundamentales (tanto sustantivas como procedimentales), requiere para resultar eficaz garantizar su condición de "norma suprema" respecto al resto de normas que componen el ordenamiento jurídico, esto quiere decir, afirmar su "carácter normativo". Esta condición, se encuadra dentro de un proceso mayor que GUASTINI denominó proceso de "constitucionalización del ordenamiento jurídico". Una de las condiciones necesarias para satisfacer la condición de "garantía jurisdiccional de la Constitución", implica el establecimiento de órganos encargados de ejercer el control constitucional de las leyes ${ }^{8}$. De esta forma, la jurisdicción constitucional, se erige como una institución encargada de la defensa de la Constitución, limitando el actuar de los poderes políticos, permitiendo el paso del Estado Legal de Derecho al Estado Constitucional de Derecho ${ }^{9}$.

De esta forma, como plantea Walter CARNOTA, su desarrollo y expansión desde fines del siglo xx hasta inicios siglo XXI, se ha caracterizado por la creación de instituciones que permitan garantizar la eficacia de las constituciones, como es el control de constitucionalidad; desde su origen "mitológico" con Marbury vs. Madison y el desarrollo posterior en la jurisprudencia de la Corte Suprema norteamericana, así como la jurisdicción constitucional en la Constitución de la República Federal de Austria (Oktoberverfassung) de 1920, han visto un enorme desarrollo posterior, creándose tribunales especializados desde países de la Europa Central u Oriental poscomunista hasta América Latina ${ }^{10}$.

Estos instrumentos de salvaguarda de la Constitución, tienen como finalidad lo que se entiende como el paso de la Constitución "formal" a la Constitución "material"; y en base a ello encontramos mecanismos establecidos para proteger las normas constitucionales y mantener su vigencia en tanto normas supremas (métodos "preventivos" o "preservativos" y por el otro, mecanismos de índole procesal orientados a proteger los preceptos constitucionales frente a una incertidumbre, violación o su desconocimiento (mecanismos "restitutivos" o "reparadores"11. De esta manera, las garantías establecidas en la Constitución permiten por un lado la el respeto y la protección de las funciones y competencias de los órganos estatales y de los funcionarios que las componen, así como de los procedimientos

7 NOGUEIRA, Humberto, “Tópicos sobre jurisdicción constitucional y tribunales constitucionales” en Revista de Derecho, Vol. XIV. (2003), pp. 43-66, p. 43.

8 GUASTINI, Ricardo, "La 'constitucionalización' del ordenamiento jurídico: el caso italiano", en CARBONELL, Miguel (Compilador), Estudios de Teoría Constitucional, México, Editorial Fontamara, 2001, pp. 154-164, pp. 155-156.

9 NOGUEIRA, Humberto, "Tópicos sobre... cit, p. 45.

10 CARNOTA, Walter, "La diferenciación entre Control de Constitucionalidad, Control de Convencionalidad y Control de Compatibilidad" en Anuario Iberoamericano de Justicia Constitucional, N 15 . (2011), pp. 51-66, p. 52.

11 NOGUEIRA, Humberto, "Tópicos sobre... cit, p. 45. 
de diversa índole (elecciones, reforma constitucional, etc.) y por el otro, la protección de los derechos fundamentales allí consagrados o reconocidos.

Sin embargo, no es posible comprender esta situación como dos procesos aislados, pues -por ejemplo- en el caso de que se considere que existen normas de rango infraconstitucional que se considere resulten violatorias a los derechos consagrados en la Constitución consagra un órgano (u órganos dependiendo de su diseño institucional) encargado del control de la Constitución, lo que implica a su vez establecer mecanismos que permitan proteger las prerrogativas otorgadas a dicho órgano. Esta función de defensa de la Constitución recaída en las cortes constitucionales, ha ido cobrando mayor centralidad en la vida de los Estados con el paso del tiempo, generando múltiples diseños institucionales, desde un modelo de control difuso, pasando por un modelo concentrado, desembocando en modelos derivados de ambos.

El primer modelo denominado "control difuso" o en el mundo anglosajón "judicial review, podemos definirlo -siguiendo a Helen HIGHTON ${ }^{2}$ - como un modelo de control de constitucionalidad el cual encarga a los jueces del Poder Judicial, la función de respetar el principio de supremacía constitucional en la aplicación de las leyes en la resolución de casos concretos, produciendo efectos inter partes. En el mismo sentido, CHANAMÉ ${ }^{13}$, afirma que el control difuso que realiza el órgano jurisdiccional es un control de inaplicabilidad en cuanto, al no aplicar una norma por considerarla incompatible con una norma de rango superior, no implica su expulsión del ordenamiento jurídico, manteniendo sus efectos fuera de las partes del proceso.

Según Mario CAPELLETTI, este modelo se caracteriza por su "perfil modal", en tanto se produce de forma incidental cuando se presenta una controversia en un caso ordinario respecto a la constitucionalidad de una ley, justificando se pronuncie además respecto a la solución del caso sobre el "incidente" carácter declarativo y limitando sus efectos respecto al caso concreto. Sin embargo, uno de los percances que puede suscitarse a raíz de la desconcentración de esta función, es que con el tiempo se pueda volver a presentar el mismo caso ante la justicia, pudiendo variar el criterio; surgiendo de ello el principio de "stare decisis", el cual implica una aplicación vertical (los órganos inferiores están obligados a guiarse por el criterio de los órganos superiores) y horizontal (los órganos judiciales deben evitar las contradicciones siguiendo sus propios precedentes) $)^{14}$.

Como señala HARO REYES ${ }^{15}$, este modelo, fue el único existente por más de un siglo, y no hubo mayores intentos en Europa por incorporar la función de control de constitucionalidad a sus jueces, probablemente debido a las "reminiscencias" de la Revolución Francesa, persistiendo la idea de la incuestionabilidad de las normas emitidas por el

12 HIGHTON, Elena, "Sistemas concentrado y difuso de control de constitucionalidad", en VON BOGDANDY, Armin, Eduardo FERRER MAC-GREGOR y Mariela MORALES ANTONIAZZI (Editores), La justicia constitucional y su internacionalización. ¿Hacia un ius constitutionale commune en América Latina, México D.F., Instituto de Investigaciones Jurídicas UNAM, 2010, pp. 107-173, pp. 108109.

${ }_{13}$ CHANAMÉ ORBE, Raúl. Diccionario de Derecho Constitucional. Lima, ARA Editores, 5ta edición, 2007 , p. 51

14 HARO REYES, Dante, "Los sistemas de control de la constitucionalidad. Comentarios de la actualidad mexicana” en Revista Jurídica Jaliscience $N^{\circ} 53$, (2015), pp. 43-70, pp. 48-49.

15 HARO REYES, Dante, "Los sistemas...cit., pp. 49-50. 
legislativo en tanto representantes del pueblo. Sin embargo, será hasta 1920 y la irrupción del modelo propuesto por Hans KELSEN, que surge un nuevo modelo: el modelo concentrado o europeo.

Para Javier PÉREZ ROYO ${ }^{16}$, las principales características de este sistema son: el control de constitucionalidad recae en un órgano distinto a los tres poderes clásicos (Poder Ejecutivo, Poder Legislativo y Poder Judicial) por lo cual se ejerce de manera concentrada por dicho órgano, el cual actúa solo a instancia de parte y basándose en criterios estrictos de legitimación, y por último su sentencia tiene la fuerza de una ley actuando el tribunal como "legislador negativo", produciendo el efecto de expulsión del ordenamiento jurídico de la norma declarada inconstitucional desde la expedición del fallo

Para poder comprender el surgimiento y desarrollo de este modelo de control de constitucionalidad, es necesario encuadrarlo dentro del proceso evolutivo en el constitucionalismo, el cual puede ser divido en tres momentos - como plantea Robert ALEXY-: primero, la formación del "Estado formal de Derecho" como respuesta a la necesidad de Estado y Derecho, luego surge el "Estado Democrático de Derecho" como respuesta a la necesidad de otorgar legitimidad democrática al Estado y a la producción del Derecho, y por último la imposición de ataduras institucionalizadas de contenido al poder democrático ${ }^{17}$. Es en este contexto que el control concentrado de constitucionalidad, se presenta como el mecanismo idóneo para hacer efectivas las Cartas de Derechos contenidas en las constituciones, consagrando un espacio "inviolable" para los poderes públicos, incluso de aquellos que poseen el mayor grado de representatividad popular, como son los órganos legislativos.

La plasmación de estos los dos modelos antes desarrollados (el modelo de control difuso y el de control concentrado) en los diversos ordenamientos y sistemas jurídicos, con el fin de adaptarlo a las necesidad de cada contexto, ha generado un proceso de "hibridación", incorporando elementos de uno u otro modelo procurando la "eficiencia", contemplando por ejemplo un órgano ad-hoc para la declaración de inconstitucionalidad, y a la vez facultando a los jueces ordinarios la inaplicación de las normas que considere inconstitucionales ${ }^{18}$.

La recepción de estos modelos a lo largo de la historia, se ha manifestado de diferentes maneras en el caso latinoamericano. De esta manera, como señala BREWER-CARÍAS, en un inicio, en la mayoría de países de la región, adoptaron el modelo de control difuso de constitucionalidad, evolucionando a la incorporación del modelo concentrado de constitucionalidad, integrado en la Corte Suprema o en tribunales constitucionales. Surgiendo posteriormente el modelo mixto al mezclarse elementos de ambos modelos, dando lugar a un tercer modelo como resultado; sin embargo para algunos estudiosos del fenómeno, lo que se ha producido algunos países latinoamericanos, no es la construcción de un modelo mixto, sino la adopción de un modelo "dual" o "paralelo", es decir, se presenta la coexistencia de ambos modelos sin mezclarse o desnaturalizarse ${ }^{19}$.

16 Citado por: QUIROZ CASTRO, Cristian y Leandro PEÑA MERINO, "Control de Constitucionalidad" en Revista Sur Academia, N 5, vol. 1, (2016), pp. 58-63, p. 61.

17 Citado por GRANDEZ, Pedro, Tribunal Constitucional y Argumentación Jurídica, Lima, Editorial Palestra, 2010, pp. 22-23

18 HARO REYES, Dante, "Los sistemas...cit., p. 52.

19 GARCÍA BELAUNDE, Domingo y Francisco EGUIGUREN PRAELI, "La evolución político-constitucional del Perú 1976-2005” en Estudios Constitucionales, Año 6, N² 2, (2008), pp. 371-398, p. 380. 


\section{UNA APROXIMACIÓN A LA DEMOCRACIA DELIBERATIVA}

La Democracia Deliberativa, en tanto teoría de la democracia ha sido concebida, por autores como HABERMAS, como un modelo que propone la superación de las "deficiencias" de las teorías liberales y republicanas de la democracia, sin desechar por ello sus principales elementos. De esta manera, si en el modelo liberal el Estado debe garantizar los derechos subjetivos, y en el modelo republicano garantizar el cumplimiento de la voluntad "popular", HABERMAS -en palabras de Héctor DOMÍNGUEZ- propone que la razón de ser del Estado debe consistir en:

"la salvaguarda de un proceso inclusivo de formación de la opinión y la voluntad común, en la que los ciudadanos libres e iguales se entienden sobre las metas y normas que serían de interés común para todos, para entenderse respecto de los criterios a partir de los cuáles se puede establecer qué es lojusto y lo injusto, es decir, establecidos los derechos, la función del Estado será garantizarlos y protegerlos para que los ciudadanos en el ejercicio de estos (derechos) no atropelle a los otros." 20 .

Es por ello, que María GUERRA, denomina a la democracia deliberativa en los términos de HABERMAS, como una "inclusión radical", en cuanto -como se desprende del párrafo anterior- todos los ciudadanos y grupos sociales se ven involucrados en la toma de decisiones públicas, en cuanto esta (la ciudadanía) ha decidido auto-determinarse, y por ello el Estado debe garantizar, tanto las libertades negativas (ligados a la libertad individual) y las libertades positivas (ligadas a derechos colectivos), los cuales serían complementarios e igual de importantes ${ }^{21}$. Conciliando ambos modelos, evitando las exclusiones que surgen cuando se imponen los derechos individuales frente a la voluntad popular, y viceversa.

Este planteamiento pondría en cuestión, a la teorías hegemónicas de la democracia del siglo XX, como el elitismo democrático o las teorías de la escuela racional como apuntan Denilson LUIS WERLE y Rúrion SOARES MELO, las cuales coinciden en que a través de mecanismos de agregación de preferencias como el voto, las instituciones que organizan el poder político deben articular los intereses individuales con los intereses generales de la comunidad política ${ }^{22}$. Precisamente, el punto débil de dicho modelo agregativo (y es el presupuesto básico de la democracia deliberativa) es el hecho de que existan profundos desacuerdos en la sociedad, los cuales pueden ser de preferencias e intereses (como plantean BARBER, HABERMAS o BOHMAN) o de carácter moral (como sostienen RAWLS, GUTMANN y THOMPSON ${ }^{23}$.

En este sentido la crítica de la democracia deliberativa parte del alejamiento de concepciones puramente cuantitativas de democracia, relacionadas solamente con la porción de la población que tiene derecho a voto, sino "se relaciona con auto-determinación, con la posibilidad de que la gente ejerza un mayor control sobre las circunstancias políticas

20 DOMÍNGUEZ, Héctor, "Democracia Deliberativa en Jurgen Habermas" en Analecta política, Vol. 4, No. 5, (2013). pp. 301-323, p. 307.

21 GUERRA, María José, Habermas: La apuesta por la democracia, Batiscafo S.L., 2015, pp. 111-112.

22 LUIS WERLE, Denilson y Rúrion SOARES MELO, Democracia Deliberativa, Sao Paulo, Editora Singular-Esfera Pública, 2007, p. 7.

23 CORTINA, Adela, "Democracia deliberativa", en: RUBIO C. José; Ana M. SALMERÓN y Manuel TOSCANO M. (Editores.), Ética, ciudadanía y democracia, Contrastes: Colección Monográfica ํㅜ 12 , Málaga, 2007, pp. 143-161, p. 146. 
y económicas de sus vidas" ${ }^{24}$. Respecto a las teorías de la democracia deliberativa, dichos autores afirman:

“(...)que los procesos de toma de decisiones tienen que estar fundados en la deliberación de los ciudadanos en fórums públicos amplios de debate y negociación. Por tanto, las prácticas e instituciones democráticas deben de tener como presupuesto la posibilidad de uso público de la razón, libre e inclusiva, según el cual las deliberaciones políticas sobre cuestiones fundamentales no resultan de un proceso mecánico de agregación de preferencias fijas y preexistentes al juego político, sino de un proceso de formación y y transformación de las propias preferencias y de los intereses particulares, en el sentido de alcanzar acuerdos políticos que tengan a su favor una pretensión de racionalidad"25 .

GUTMANNy THOMPSON, caracterizan a la concepción de la democracia deliberativa como un proceso en el cual los deliberantes intercambian razones con el fin de alcanzar “justos términos de cooperación social”, esgrimiendo razones que deben ser públicamente accesibles a todos los afectados, por una medida política la cual, deberá ser vinculante para todos los ciudadanos durante un periodo determinado de tiempo, resaltando su provisionalidad moral y política ${ }^{26}$. Lo que se traduce en la posibilidad de reaperturar el diálogo en cualquier momento, cuando se produzcan las condiciones necesarias y bajo los procedimientos establecidos para dicho propósito.

Podemos encontrar una definición mínima de democracia deliberativa en ELSTER, quien afirma que la noción de democracia deliberativa incluye, dos aspectos. Por un lado el aspecto democrático, el cual implica "una toma de decisiones colectiva con la participación de todos aquellos que resultarán afectados por la decisión, o de sus representantes"27. El otro aspecto, que sería fundamental, para caracterizar y diferenciar esa concepción de la democracia de otras, el aspecto deliberativo, "que esta decisión debe ser tomada mediante argumentos ofrecidos por y a los participantes, que están comprometidos con los valores de racionalidad e imparcialidad"28 .Jose Luis MARTÍ, señala que esta definición de ELSTER, si bien adecuada como definición mínima, omite un elemento muy importante; la democracia deliberativa tiene un carácter ideal, constituye un "ideal regulativo", entendido como: "un horizonte normativo hacia el que debemos tender en la medida de lo posible. (...) un estado de cosas que evaluamos como deseable o correcto (...) puede ser empíricamente alcanzable o no alcanzable, sin que ello afecte a la validez normativa del ideal" 29 . Es decir, su fundamento no es necesariamente empírico, no depende de un determinado estado de cosas, sin embargo al pasar a un segundo momento evaluativo, este ideal regulativo se traduce en algunas condiciones empíricas.

Nicolás Emanuel OLIVARES, a partir de una lectura de MARTÍ, GUTMANN, y THOMPSON, RAWLS, NINO entre otros, plantea la descomposición del concepto de democracia deliberativa en tres elementos: ideal regulativo, sujeto y proceso. El primero entendido como la oposición al ideal democrático agregativo, expresado en la negociación y

\footnotetext{
24 GUERRA, María José, Habermas: La apuesta...cit., p.112.

25 LUIS WERLE, Denilson y Rúrion SOARES MELO, Democracia Deliberativa...cit., pp. 7-8.

26 Citados por OLIVARES, Nicolás Emanuel, "Democracia deliberativa... cit., p. 169.

27 MARTÍ, José Luis, La República Deliberativa, Madrid, Marcial Pons, 2006, p. 23.

28 MARTÍ, José Luis, La República...cit., p. 23.

29 MARTÍ, José Luis, La República...cit., p. 25
} 
el voto, proponiendo la argumentación como método político, es decir, que "las normas y medidas políticas son democráticamente legítimas si y solo si resultan de la deliberación pública entre ciudadanos y representantes, y están justificadas en aquellas razones públicas que resultan aceptables para los deliberantes" ${ }^{30}$. Respecto al sujeto, la democracia deliberativa basada en los principios de inclusión, igualdad e imparcialidad, postula que en el proceso deliberativo todos los ciudadanos "deben ser tratados como agentes morales y epistémicamente capacitados para intervenir en el debate público y tomar decisiones políticas; (...) deben escucharse, respetarse y discutirse los argumentos de todos los posibles afectados por la norma o medida política en cuestión" ${ }^{31}$. Sobre el proceso, señala que, el ideal regulativo se debe materializar a través de proceso de discusión para la toma de decisiones políticas, adoptando un criterio "epistémico intersubjetivo de validación de resultados", contrastando con los modelos de democracia agregativa, comprendiendo a las preferencias como estáticas, siendo sus resultados posibles de ser revisados en un proceso que observe que cumpla con los criterios de: "respeto mutuo entre ciudadanos, así como facilitar la resolución de aquellos desacuerdos políticos-morales existentes en una determinada sociedad"32.

De esta manera, la democracia deliberativa en tanto ideal regulativo, nos conduce a establecer como condición de legitimidad democrática de las normas, instituciones y medidas políticas -tal como señala Nicolás OLIVARES- "la existencia de un proceso intersubjetivo de justificación moral, en el cual los afectados por dicha decisión deliberen públicamente entre sí" ${ }^{33}$. El cumplimiento de tales condiciones produciría "un resultado justo y políticamente vínculante" 34 , este sería la finalidad primordial y el fundamento de la reflexión sobre las condiciones de la legitimidad democrática de la democracia deliberativa.

\section{CONTROL DE CONSTITUCIONALIDAD Y DEMOCRACIA DELIBERATIVA}

Como tratamos anteriormente, el control de constitucionalidad, entendido como la potestad del juez de revisar la conformidad de una norma con el contenido de la constitución, y que en su modalidad concentrada, implica la expulsión del sistema jurídico de la norma que no apruebe dicho test. Esta facultad ha generado amplia discusión, desde su origen (los debates en "El Federalista" en los orígenes de los Estados Unidos ${ }^{35}$ ), cuestionándose aspectos como el grado de representatividad de los jueces respecto a los ciudadanos y por qué deberían poder derogar una norma dada por el legislativo, siendo que esta norma posee mayor grado de legitimidad.

30 OLIVARES, Nicolás Emanuel, "Democracia deliberativa... cit., pp. 179-180.

31 OLIVARES, Nicolás Emanuel, "Democracia deliberativa... cit, p. 181.

32 OLIVARES, Nicolás Emanuel, "Democracia deliberativa... cit, p. 182

33 OLIVARES, Nicolás Emanuel, "Democracia deliberativa... cit, p. 169.

34 ALLES, Nicolás, "El problema de la legitimidad en la democracia deliberativa”. VII Jornadas de Jóvenes Investigadores. Instituto de Investigaciones Gino Germani, Buenos Aires, (2013), Facultad de Ciencias Sociales - Universidad de Buenos Aires, p. 2

35 GARCIA, José Francisco. "Tres aportes fundamentales de El Federalista a la Teoria Constitucional Moderna” en Revista de Derecho, Vol. XX - Nº1, (2007). pp. 39-59. 
De esta manera surgieron propuestas como la de "representación argumentativa" de Robert ALEXY ${ }^{36}$, para poder resolver esta situación, sin embargo dicha propuesta -entre otras que pretenden legitimar dicha función, sin proponer reformas institucionales- no ha podido apartar el tema del control judicial del debate constitucional, como lo prueba el surgimiento de corrientes como el Constitucionalismo Popular, quien pone dicho asunto como principal punto en su agenda normativa, proponiendo algunos autores, la supresión de dicha institución con el fin de "recuperar" la democracia de las manos de los jueces ${ }^{37}$.

Sin embargo, frente a ambas posturas extremas, basadas en dos modelos de democracia difícilmente reconciliables, surge un modelo que pretende superar la que concibe como una larga discusión entre liberales y republicanos $\left(\mathrm{HABERMAS}^{38}\right)$, proponiendo una serie de condiciones y principios por el cual se debe regir el proceso para la toma de decisiones públicas, garantizando la participación de todos los ciudadanos que puedan verse afectados, de manera inclusiva y en condiciones de igualdad. Esto implica un análisis del diseño institucional, no solo del control de constitucionalidad, sino en un plano mayor del propio sistema de frenos y contrapesos en la manera en la que se produce el diálogo entre los órganos estatales, y entre estos y los ciudadanos, a fin de determinar si dichos arreglos institucionales resultan "antagónicos y elitistas se corresponden con concepciones igualmente elitistas de la política, lo que es un rasgo común tanto del liberalismo como del conservadurismo en nuestro continente americano: mantener a la colectividad de los ciudadanos lo más lejos posible de los ámbitos públicos de decisión” 39 .

De esta manera, para pasar a un momento evaluativo, es necesario determinar el tipo de discurso al que nos referimos, en este caso el "discurso constitucional". Para la teoría del discurso los derechos tienen una dimensión ética, política y moral que hacen que en la deliberación constitucional como discurso práctico se involucren razones pragmáticas, éticas y morales que se refieren a la precisión y ponderación de fines colectivos, la construcción y selección de estrategias aptas para la consecución de esos fines, orientaciones valorativas y la configuración de programas que sean buenos para todos por igual. ${ }^{40}$

Habiendo identificado las particularidades del control de constitucionalidad y haber descrito el modelo deliberativo de democracia, como advierte Donald BELLO es posible afirmar que "El control de constitucionalidad se vuelve una institución incómoda para comprensión deliberativa del proceso democrático, pues excluye de la deliberación a un gran número de sujetos que pudieran estar potencialmente afectados por las decisiones de un

36 GARGARELLA, Roberto. "Alexy y la Representación Argumentativa de los Tribunales”. Disponible en: http://www.constitucionalista.net/alexy-y-la-representacion-argumentativa-de-los-tribunales/

37 NIEMBRO, Roberto, La justicia constitucional de la democracia deliberativa. Tesis para optar el grado de Doctor. Departamento de Derecho Constitucional, Facultad de Derecho, Universidad Complutense de Madrid, 2017, p. 199.

38 PINEDA GARFIAS, Rodrigo. "La Democracia Deliberativa” en Revista Ius et Praxis, vol.8, n.2, (2002), Talca. Disponible en: https://scielo.conicyt.cl/scielo.php?script=sci_abstract\&pid=S071800122002000200020\&lng=es\&nrm=iso\&tlng=es

39 DÁZ DEL CASTILLO, "Andrés, Control judicial, reforma constitucional y diálogo institucional. Apuntes críticos al modelo colombiano desde una perspectiva deliberativa”, Revista Ratio Juris Vol. 10 N. 20. (2015) pp. 213-238, p. 235.

40 LINARES, Sebastián, "El Control de Constitucionalidad, la democracia deliberativa epistémica y la dificultad contramayoritaria" en SPECTOR, Ezequiel y Jorge Luis FABRA, Enciclopedia de filosofía y teoría del derecho, Vol. 3, México, UNAM, 2015, pp. 1959-1990, p. 1967. 
tribunal"41. Es por ello que algunos teóricos de la democracia deliberativa, en este segundo momento se propusieron analizar las "implicancias institucionales" de su propuesta, identificado el grado de reforma que conllevaría en los esquemas institucionales actuales, como señala Nicolás OLIVARES "En este marco reformista ha recibido una especial atención la incógnita relativa a cuál es el mejor mecanismo deliberativo de control de constitucionalidad por adoptar" ${ }^{\prime 2}$.

\section{III.1. La revisión judicial dialógica}

Como apunta Roberto NIEMBRO, frente a las posiciones favorables a la supremacía judicial y han institucionalizado la "última palabra" (como en las visiones "neoconstitucionales" y que hacen de la interpretación constitucional una actividad "monológica" y autorreferencial, se antepone una visión dialógica de la función de los jueces, donde frente al modelo de juez "Hércules" planteado por autores como DWORKIN, antepone el "juez Pericles", el cual no cree tener la única respuesta correcta "sino y estima valiosa y necesaria la colaboración entre poderes y la participación ciudadana. (...) un juez abierto al aprendizaje y comprometido con el cumplimiento de los derechos a través del respeto y enriquecimiento de los espacios de deliberación democrática" ${ }^{43}$.Roberto GARGARELLA identifica cuatro expresiones de este modelo "dialógico" de constitucionalismo en las últimas décadas, en la cláusula de "no obstante" incorporada en la reforma de la Carta de Derechos canadiense de 1982, el "nuevo modelo constitucional del Commonwealth", el derecho a la consulta previa establecido en el Convenio $\mathrm{N}^{\circ} 189$ de la OIT de 1989, y las prácticas dialógicas que se han producido en América Latina, relacionadas con graves e importantes casos de violaciones de los derechos, frente a los cuales algunos Tribunales en esta región han propiciado el diálogo (en Brasil, Argentina y Colombia principalmente) ${ }^{44}$.

Sin embargo, es necesario señalar que las críticas de GARGARELLA, al control de constitucionalidad -al menos de la manera en que ha sido desarrollado en situaciones "normales" en América Latina- se basan en las siguientes presupuestos: cada persona es la última autoridad respecto a la forma de vida que prefiere llevar; cuando se presentan cuestiones que trascienden la moral privada, debe existir un proceso de reflexión colectiva, procurando la imparcialidad a partir de la intervención de todos los posibles afectados, siendo que lo la reflexión pública puede acercarnos a cumplir tal fin; los actuales modelos no favorecen la toma de decisiones colectivas; si bien debe existir algún tipo de control, no es "obvio" que deba ejercerse como se ha ejercido, sobre todo al establecer la supremacía judicial y por último, considerar la falibilidad de cualquier mecanismo institucional, estableciendo modelos alternos ${ }^{45}$.

${ }^{41}$ BELLO, Donald Emerson, "Revisión judicial y democracia deliberativa en términos de teoría departamental y constitucionalismo popular", en Bajo Palabra - Revista de Filosofía, n 17, (2017), pp. 191212 , p. 193.

42 OLIVARES, Nicolás, "Democracia deliberativa...cit., p. 170.

${ }_{43}$ NIEMBRO, Roberto, La justicia constitucional...cit., p. 110.

44 GARGARELLA, Roberto, "El nuevo constitucionalismo dialógico, frente al sistema de los frenos y Contrapesos" en GARGARELLA, Roberto (Compilador), Por una justicia dialógica: el Poder Judicial como promotor de la deliberación democrática, Buenos Aires, Siglo Veintiuno Editores, 2014, pp. 119158, pp. 119-120.

45 GARGARELLA, Roberto, La Justicia frente al gobierno, Corte Constitucional de Ecuador, 2011, Quito, pp. 279-280. 
Roberto GARGARELLA, parte de la crítica a quienes sostienen que es posible interpretar como dialógico el proceso de control de constitucionalidad por el solo hecho de intervenir las partes presuntamente afectadas -por ejemplo-, pese a que elórganojudicial posee la "última palabra" institucional respecto al contenido de la Constitución. De esta manera, señala que el diálogo -desde su punto de vista-, presupone que los argumentos deben tener igual posibilidad de prevalecer, sin embargo en dichas condiciones, existe un desequilibrio, lo que implica que en los hechos ya no es la gente sino la rama "menos democrática" la que tiene la suprema autoridad constitucional ${ }^{46}$.

Respecto al modelo deliberativo al cual se adhiere el autor, sugiere que los problemas relacionados con la "moralidad inter-personal" 47 , deben resolverse a través de un proceso colectivo de reflexión a través de la exposición de información y corrección mutua entre los participante, agregando un valor epistémico a dicha práctica, pues de lo contrario-señalase corre el riesgo de tomar una decisión ignorando, malinterpretando y sin respetar los puntos de vista de los afectados, constituyendo la deliberación una herramienta que asegura la imparcialidad de los jueces ${ }^{48}$.

En su obra "La Justicia frente al Gobierno", Roberto GARGARELLA esboza una propuesta alternativa a la potestad de tener la última palabra respecto a la interpretación constitucional de los jueces constitucionales y vincularlos con los grupos sociales más vulnerables ${ }^{49}$; proponiendo que la función judicial de control de constitucionalidad en clave dialógica debe orientarse bajo los siguientes fines:

(i) Asegurar las condiciones del debate democrático: Implica la autorización de la intervención judicial frente a la legislación que presente las siguientes características: a) permita la discriminación irracional de los grupos minoritarios, b) impida el derecho de reunión o discusión individual, censure las vías de expresión y medios de comunicación, c) distorsione la voluntad mayoritaria (y el proceso electoral), d) Distorsione el proceso político de toma de decisiones, y e) desvirtúe los controles orientados a fiscalizar el desempeño de sus funciones desvirtuar los controles destinados a fiscalizar sus acciones, o los medios orientados a evaluarlas o perfeccionarlas, etc..$^{50}$

(ii) Asegurar una esfera de inviolable autonomía en los individuos: Ello con el fin de permitir a los ciudadanos tener la potestad de determinar el modelo de vida que

46 GARGARELLA, Roberto, The Scepter of Reason: Public Discussion and Political Radicalism in the Origins of Constitutionalism, Dordrech , Springer Science+Business Media, 2000, p. 114.

47 Planteamiento de Carlos Nino para justificar la revisión judicial de las leyes desde la democracia deliberativa. El autor señala que la revisión judicial debe orientarse a determinar que las decisiones colectivas no se basen en modelos de "perfeccionamiento moral", sino solo bajo criterios derivados de la "moralidad intersubjetiva", lo que se determina al analizar las razones del procedimiento argumentativo. De esta forma como señala el autor: "a través de la limitación de la esfera de la constitución ideal del poder a cuestiones de moral intersubjetiva, se puede percibir el dominio de la constitución ideal de los derechos, donde se ve involucrado el reconocimiento de la autonomía. El derecho a no ser coercionado sobre la base de modelos de excelencia personal es, de este modo, parte de este grupo de derechos a priori que son condición del proceso democrático". NINO, Carlos, La constitución de la democracia deilberativa, Barcelona, Gedisa, 1997, pp. 277-280.

48 GARGARELLA, Roberto, The Scepter...cit., pp. 128-129.

49 GARGARELLA, Roberto, La justicia frente...cit., p. 281.

50 GARGARELLA, Roberto, La justicia frente...cit., p. 280. 
prefieran, de esta manera los jueces constitucionales deben: a) impedir la interferencia: de los poderes públicos respecto a la moral privada a través de leyes perfeccionistas, b) contribuir a los órganos políticos a erigir un modelo adecuado de protección para que los individuos puedan llevar a cabo sus ideales de "virtud personal”, c) asimismo plantea establecer mecanismos que permitan recolectar la opinión de sectores minoritarios afectados o abrir canales directos para quienes puedan verse afectados pese a ser un grupo muy pequeño y poco "poder de presión” sean escuchados ${ }^{51}$.

De esta manera, el juez en el proceso de control de constitucionalidad actúa además de garante de aquellos presupuestos que permitan la interacción dialógica entre la sociedad civil y los órganos estatales (en este caso fundamentalmente el órgano judicial, y de aquel con los otros órganos), así como corregir o garantizar el acceso a dicho proceso comunicativo a grupos que puedan verse jurídica y fácticamente excluidos o marginados, garantizando su autonomía, para que el proceso de diálogo se produzca en condiciones de igualdad.

En este sentido, al momento que "superamos" la supremacía judicial y aceptamos que a la par de servir están subordinados al debate público, se convierten en un elemento esencial del mismo, transformándose en el "motor" de la deliberación; ello debido a que se encuentra en una buena posición para realizar esta tarea, ya que su función principal es recibir las demandas de quienes se han visto afectados o han sido marginados por las ramas políticas, convirtiéndose en la principal vía que tienen los grupos desfavorecidos para solicitar la atención de sus reclamos, así como tienen la facultad de exigir una mayor grado de justificación de las decisiones tanto de las personas como de sus representantes. Para ello, el juez debe garantizar la existencia de condiciones de igualdad, lo que implicaría algún tipo de activismo, respecto a la tutela de derechos sociales que permitan la participación política en dichas condiciones ${ }^{52}$. De esta manera, se trae a colación el problema sobre las precondiciones de la democracia deliberativa, la existencia de derechos que deben ser garantizados para el desarrollo eficaz del proceso dialógico, pudiendo generar una tensión entre posturas procedimentalistas y sustancialistas de la democracia deliberativa.

\section{III.2. LA revisión judicial de la división de poderes deliberativa}

El planteamiento de una división de poderes deliberativa, parte de la idea-siguiendo a TULIS- de que ninguna de las instituciones de una democracia es suficiente para considerar todas las preocupaciones relativas a su sostenimiento, y en este sentido, al proponer la deliberación como criterio dominante de legitimidad, establece una categoría para la medición del grado de interacción institucional: la "performance deliberativa" 53 .

Para MENDES, las discusiones sobre la legitimidad se han desarrollado de manera dicotómica, por un lado quienes privilegian la forma y por el otro los que privilegian el fondo,

51 GARGARELLA, Roberto, La justicia frente...cit., pp. 280-281.

52 GARGARELLA, Roberto, Theories of Democracy, the Judiciary and Social Rights, en GARGARELLA, Roberto; Pilar DOMINGO y Theunis ROUX (Editores), Courts and Social Transformation in New Democracies: An institutional voice of the poor?, Hampshire, Ashgate Publishing Limited, 2006, pp.1334, pp. 28-29.

53 MENDES, Conrado H., "Una división de poderes deliberativos entre el diálogo y la última palabra", en GARGARELLA, Roberto (Compilador) Por una justicia dialógica: el poder judicial como promotor de la deliberación democrática, Siglo XXI Editores Argentina, 2014, pp. 159-185, p. 169. 
lo que ha llevado a sostener indesafiabilidad del parlamento y por el otro la infalibilidad de las cortes. Frente a estas dos situaciones el autor realiza la siguiente crítica: en el primer caso cierra la puerta a cualquier crítica de carácter sustantivo fuera de los propios canales parlamentarios, lo que dificulta la posibilidad que se den a conocer las resistencias a decisiones que vulneren la "razón pública" (concepto prestado de RAWLS) de manera más evidente, es por ello que la revisión judicial genera un límite externo, manteniendo en agenda el debate sobre las restricciones al parlamento, en cuanto lo obliga a justificar su accionar en base a las precondiciones de la democracia, vitalizando la razón pública a partir del diálogo $0^{54}$. Sin embargo, esta función -advierte- posee ciertos riesgos: "el legalismo hermético, el imperialismo retórico, los antecedentes socieconómicos conservadores de los jueces, la arrogancia del guardián atrincherado y monopólico; del otro lado, la pasividad legislativa, la condescendencia y la complacencia"55.

Estos riesgos pueden ser reducidos (en tanto el autor no cree en la infalibilidad a priori de las instituciones, sino al igual que RAWLS mantiene una posición basada en términos "probabilísticos"), al desarrollar una exigencia mayor de diálogo entre instituciones, lo que implica que al momento de disentir, no se presuponga que una rama posee mayores destrezas que la otra; de esta manera:

"La interacción entre instituciones que procuran llevar al máximo sus respectivos desempeños deliberativos es lo mejor que podemos esperar de una democracia organizada bajo el principio de división de poderes. Estimula la búsqueda del mejor argumento einculca en el régimen la vibración racional y la presión de alcanzar una mayor consistencia... es posible pensar la legitimidad del parlamento y cortes de una manera contextual y comparativa...La legitimidad política es una propiedad institucional volátil que depende en parte de los resultados y en parte de sus credenciales formales. Es una meta que alcanzar y preservar en cada decisión" ${ }^{\prime 56}$.

De esta forma, será a partir de su "desempeño" que resultarán legitimadas las decisiones, entendiendo este desempeño como una práctica de diálogo, de esbozo de argumentos y contra-argumentos, en un proceso en el cual ambas instituciones se empujan unas a otras a elaborar mejores justificaciones. Esto no podría ser posible sin la separación de poderes, en tanto primera condición, sin embargo la interacción que surge en la práctica puede tomar diversos caminos, en este caso, el planteamiento de MENDES propone la deliberación y el diálogo como el camino ideal para potenciar las credenciales democráticas de dichos órganos, más allá de cuestiones que considera puramente procedimentales como quien tiene la última palabra, lo que desde esta perspectiva, no otorgaría tampoco una legitimidad per se. Es por ello que el autor concluye respecto a la revisión judicial, que es un "mecanismo que propulsa la existencia de una mejor y mayor deliberación, al menos sobre cuestiones constitucionales fundamentales. No tiene como único propósito protegernos de la política cuando esta sucumbe al pánico y la irracionalidad, sino también el de desafiarla a seguir buscando mejores respuestas" ${ }^{\text {57 }}$.

${ }^{54}$ MENDES, Conrado H., "Una división de...cit., p. 175

${ }_{55}$ MENDES, Conrado H., "Una división de...cit., p. 177

${ }^{56}$ MENDES, Conrado H., "Una división de...cit., p. 177

57 MENDES, Conrado H., "Una división de...cit., p. 183. 
Además de lo planteado anteriormente, respecto al control de constitucional basado en la interacción interinstitucional, Conrado H. MENDES plantea un modelo ideal de deliberación política en sede judicial, lo que equivaldría a una serie de normas que guiarían el proceso interno de discusión y reflexión entre los jueces, lo que permitiría obtener resultados menos excluyentes. Es por ello que, como anota Roberto NIEMBRO, al no presentar un modelo de prácticas específicas que deben ejecutarse o institucionalizarse orientado a un modelo deliberativo, plantea este conjunto de normas como una construcción ideal, dividiendo este proceso en tres etapas: la primera, el respeto que deben tener los jueces hacia a los participantes en el proceso, escuchando, entendiendo y preguntando; en segundo momento deben actuar de manera colegiada, evitando el uso arbitrario del voto individual, cooperando y dialogando, dejando de lado las preconcepciones individuales, partiendo de la posibilidad de estar equivocado y cambiar de opinión a partir de los argumentos de sus compañeros teniendo como fin la decisión colectiva, considerando además los puntos de vista de las personas presuntamente afectadas que no fueron expuestas en la audiencia (como un ejercicio de "empatía deliberativa"); y por último la sentencia, además de reconocer la posibilidad de error y provisionalidad (en tanto presupuestos de la democracia deliberativa) su coherencia narrativa debe estar redactada de forma que pueda ser comprendida fuera delámbitojurídico ${ }^{58}$.

De esta manera, MENDES enfatiza más allá del diseño institucional, en lo que podríamos denominar una "actitud deliberativa" o "actitud dialógica" que deben tener los jueces para poder cumplir con los fines de la democracia deliberativa; consciente de que las prácticas judiciales no solo se orientan a partir de las condiciones del propio sistema, sino que existen un elemento subjetivo, el cual no es posible dejar de lado, o que su inobservancia -consideramos- deja incompleto cualquier proceso de reforma.

\section{A MODO DE CONCLUSIÓN}

Los cuestionamientos a la legitimidad de los jueces para ejercer el control de constitucionalidad, desde la teoría de la democracia deliberativa y del constitucionalismo dialógico -en tanto derivado del primero-, consideramos se basan en la posibilidad de que por un lado, bajo determinado condiciones derivadas de su diseño institucional se desarrollen exclusiones (por ejemplo al consagrarse la posición de las cortes como "supremo intérprete de la Constitución" o al no establecer interacción alguna con otros órganos como el Poder Legislativo en el proceso de deliberación) y por el otro, en la ausencia de una práctica judicial orientada a la inclusión de los grupos más vulnerables o que difícilmente pueden encontrarse representados efectivamente en el proceso producto de situaciones fácticas (grupos marginados y con un alto grado de vulnerabilidad por ejemplo) y jurídicas (producto de omisiones legislativas que impidan hacer efectivos los derechos sociales reconocidos constitucionalmente, que puedan potenciar y garantizar su participación en el proceso por ejemplo).

Sin embargo, como hemos podido observar, respecto a las posiciones de GARGARELLA y MENDES, no existe consenso sobre la forma de revestir de un carácter "dialógico" al proceso de control de constitucionalidad en sede judicial, lo que se explica en tanto la

${ }^{58}$ NIEMBRO, Roberto, La justicia...cit., pp. 201-202. 
democracia deliberativa al ser un ideal regulativo, implica una acercamiento en mayor o menor grado a sus fines a partir del cumplimiento de sus presupuestos, mas no presenta una única "receta" para ello, por lo que se mantiene aún como una discusión en curso.

\section{BIBLIOGRAFÍA}

ALLES, Nicolás, "El problema de la legitimidad en la democracia deliberativa". VII Jornadas de Jóvenes Investigadores. Instituto de Investigaciones Gino Germani, Buenos Aires, (2013), Facultad de Ciencias Sociales - Universidad de Buenos Aires.

ÁLVAREZ, Ramiro, "El Constitucionalismo Popular y los problemas de la 'última palabra': apuntes para un Contexto Latinoamericano" en Revista Jurídica de la Universidad de Palermo Año 13, N¹, (2012), pp. 75-125.

BELLO, Donald Emerson, "Revisión judicial y democracia deliberativa en términos de teoría departamental y constitucionalismo popular", en Bajo Palabra - Revista de Filosofía, n 17, (2017), pp. 191-212.

CARNOTA, Walter, "La diferenciación entre Control de Constitucionalidad, Control de Convencionalidad y Control de Compatibilidad" en Anuario Iberoamericano de Justicia Constitucional, $\mathrm{N}^{\circ}$ 15. (2011), pp. 51-66.

CHANAMÉ ORBE, Raúl. Diccionario de Derecho Constitucional. Lima, ARA Editores, 5ta edición, 2007.

CORTINA, Adela, "Democracia deliberativa", en RUBIO C. José; Ana M. SALMERÓN y Manuel TOSCANO M. (Editores.), Ética, ciudadanía y democracia, Contrastes: Colección Monográfica $\mathrm{N}^{\circ} 12$, Málaga, 2007, pp. 143-161

DÍAZ DEL CASTILLO, "Andrés, Control judicial, reforma constitucional y diálogo institucional. Apuntes críticos al modelo colombiano desde una perspectiva deliberativa", Revista Ratio Juris Vol. $10 \mathrm{~N}^{\mathrm{o}}$ 20. (2015) pp. 213-238.

DOMÍNGUEZ, Héctor, "Democracia Deliberativa en Jurgen Habermas” en Analecta política, Vol. 4, No. 5, (2013). pp. 301-323.

GARGARELLA, Roberto. "Alexy y la Representación Argumentativa de los Tribunales". Disponible en: http://www.constitucionalista.net/alexy-y-la-representacion-argumentativa-de-lostribunales/

GARGARELLA, Roberto, "El nuevo constitucionalismo dialógico, frente al sistema de los frenos y Contrapesos" en GARGARELLA, Roberto (Compilador), Por una justicia dialógica: el Poder Judicial como promotor de la deliberación democrática, Buenos Aires, Siglo Veintiuno Editores, 2014, pp. 119-158.

GARGARELLA, Roberto, La Justicia frente al gobierno, Corte Constitucional de Ecuador, 2011, Quito. GARGARELLA, Roberto, Theories of Democracy, the Judiciary and Social Rights, en GARGARELLA, Roberto; Pilar DOMINGO y Theunis ROUX (Editores), Courts and Social Transformation in New Democracies: An institutional voice of the poor?, Hampshire, Ashgate Publishing Limited, 2006, pp.13-34.

GARGARELLA, Roberto, The Scepter of Reason: Public Discussion and Political Radicalism in the Origins of Constitutionalism, Dordrech, Springer Science+Business Media, 2000.

GARCÍA BELAUNDE, Domingo y Francisco EGUIGUREN PRAELI, "La evolución políticoconstitucional del Perú 1976-2005” en Estudios Constitucionales, Año 6, N² 2, (2008), pp. 371398.

GARCIA, José Francisco. "Tres aportes fundamentales de El Federalista a la Teoria Constitucional Moderna" en Revista de Derecho, Vol. XX - Nº 1, (2007). pp. 39-59.

GIUFFRÉ. Carlos, "Democracia deliberativa: institucionalización de instrumentos jurídicodialógicos", Sistema Argentino de Información Jurídica, (2016), p. 2. Disponible en: http:// www.saij.gob.ar/ 
GRANDEZ, Pedro, Tribunal Constitucional y Argumentación Jurídica, Lima, Editorial Palestra, 2010.

GUASTINI, Ricardo, "La 'constitucionalización' del ordenamiento jurídico: el caso italiano”, en CARBONELL, Miguel (Compilador), Estudios de Teoría Constitucional, México, Editorial Fontamara, 2001, pp. 154-164

GUERRA, María José, Habermas: La apuesta por la democracia, Batiscafo S.L., 2015.

HARO REYES, Dante, "Los sistemas de control de la constitucionalidad. Comentarios de la actualidad mexicana" en Revista Jurídica Jaliscience N 53, (2015), pp. 43-70.

HIGHTON, Elena, "Sistemas concentrado y difuso de control de constitucionalidad", en VON BOGDANDY, Armin, Eduardo FERRER MAC-GREGOR y Mariela MORALES ANTONIAZZI (Editores), La justicia constitucional y su internacionalización. ¿Hacia un ius constitutionale commune en América Latina, México D.F., Instituto de Investigaciones Jurídicas UNAM, 2010, pp. 107-173.

LINARES, Sebastián, "El Control de Constitucionalidad, la democracia deliberativa epistémica y la dificultad contramayoritaria" en SPECTOR, Ezequiel y Jorge Luis FABRA, Enciclopedia de filosofía y teoría del derecho, Vol. 3, México, UNAM, 2015, pp. 1959-1990.

LÓPEZ HIDALGO, Pablo. "Legitimidad democrática e interpretación de la Constitución: proyección a la tarea interpretativa de la Corte Constitucional del Ecuador", Tesis para obtener el grado de Doctor en Derecho, Universidad Andina Simón Bolívar, Quito, 2017.

LUIS WERLE, Denilson y Rúrion SOARES MELO, Democracia Deliberativa, Sao Paulo, Editora Singular-Esfera Pública, 2007.

MARTÍ, José Luis, La República Deliberativa, Madrid, Marcial Pons, 2006.

MENDES, Conrado H., "Una división de poderes deliberativos entre el diálogo y la última palabra”, en GARGARELLA, Roberto (Compilador) Por una justicia dialógica: el poder judicial como promotor de la deliberación democrática, Siglo XXI Editores Argentina, 2014, pp. 159-185.

NIEMBRO, Roberto, La justicia constitucional de la democracia deliberativa. Tesis para optar el grado de Doctor. Departamento de Derecho Constitucional, Facultad de Derecho, Universidad Complutense de Madrid, 2017.

NINO, Carlos, La constitución de la democracia deilberativa, Barcelona, Gedisa, 1997

OLIVARES, Nicolás Emanuel, "Democracia deliberativa y control de constitucionalidad: En defensa de un diseño multisituado" en Revista de Derecho (Barranquilla) № 47, (2017), pp. 167-206.

PINEDA GARFIAS, Rodrigo. "La Democracia Deliberativa" en Revista Ius et Praxis, vol.8, n.2, (2002), Talca. Disponible en: https://scielo.conicyt.cl/scielo.php?script=sci_abstract\&pid $=\mathrm{S} 0718-00122002000200020 \& \operatorname{lng}=\mathrm{es} \& \mathrm{nrm}=\mathrm{i}$ so\&tlng $=\mathrm{es}$

QUIROZ CASTRO, Cristian y Leandro PEÑA MERINO, "Control de Constitucionalidad" en Revista Sur Academia, N 5, vol. 1, (2016), pp. 58-63.

SANIN, Ricardo, Teoría crítica constitucional: rescatando la democracia del liberalismo. Quito, Corte Constitucional para el Período de Transición, 2011

SANTIAGO, Alfonso. "Sistema Jurídico, Teoría del Derecho y Rol de los Jueces: Las novedades del neoconstitucionalismo" en Revista Díkaion N²2, vol. 17. (2008), pp. 131-155.

Fecha de recepción: 30 de mayo 2018.

Fecha de aceptación: 27 junio 2018. 